\title{
THE FOREIGN PATIENT WHO WOULDN'T SPEAK - SELECTIVE MUTISM AND ITS DIAGNOSTIC CHALLENGES AT AN EMERGENCY SERVICE
}

Lascasas D; Samouco A.

ULSกA+

Unidade Local de Saúde do Norte Alentejano EPE, Departamento de Psiquiatria e Saúde Mental, Portalegre, Portugal
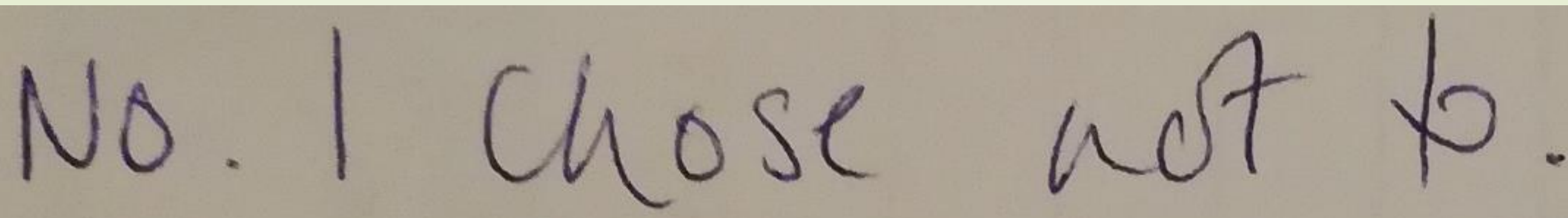

Objectives: To describe a clinical case of selective mutism (SM) at an emergency service and its diagnostic challenges.

Background: SM is an anxiety disorder (1) characterized by persistent failure to speak in certain social situations but not others. SM is often diagnosed in early childhood (2), but it can also be present in adults (3). Differential and comorbid diagnosis include autism spectrum disorder, speech/development disorders, hearing impairment, psychosis, dissociative states and mood disorders (3).

Materials and methods: Description of a clinical case and search on Pubmed data base.

\section{Can you talk to us?}

For me, this is not possible because l'd rather write.

$$
\begin{aligned}
& \text { for me, this is not possible becans } \\
& \text { I'd rather write. }
\end{aligned}
$$

Results: A 39 years old female foreign patient from the United Kingdom was brought by the police to the emergency service of Hospital of Portalegre after presenting bizarre behaviour when aproached by the police. After finding no relevant physical or laboratory findings except voluntary mutism (VM) and positive screening for amphetamines and cannabis, Psychiatric assessment was solicited. The state of consciousness revealed no changes, the attitude was collaborative, behaviour was adequate and the patient communicated through wiriting. She was able to hear and showed no comprehension deficits. The patient described being able to speak but choosing not to, although recognising how innapropriate it could look to other people. Delusions and halucinatory activity were excluded, as well as the possibility of being afraid of legal consequences concerning drugs use. In her point of view, writing was a valid communication choice, not motivated by fear of any kind, and she admitted to speak to friends. She was discharged after reavealing no relevant psychopathology besides VM.

What's the difference between communication through speaking and writing?

There is no difference. I can write using the same processes as talking in the mind.

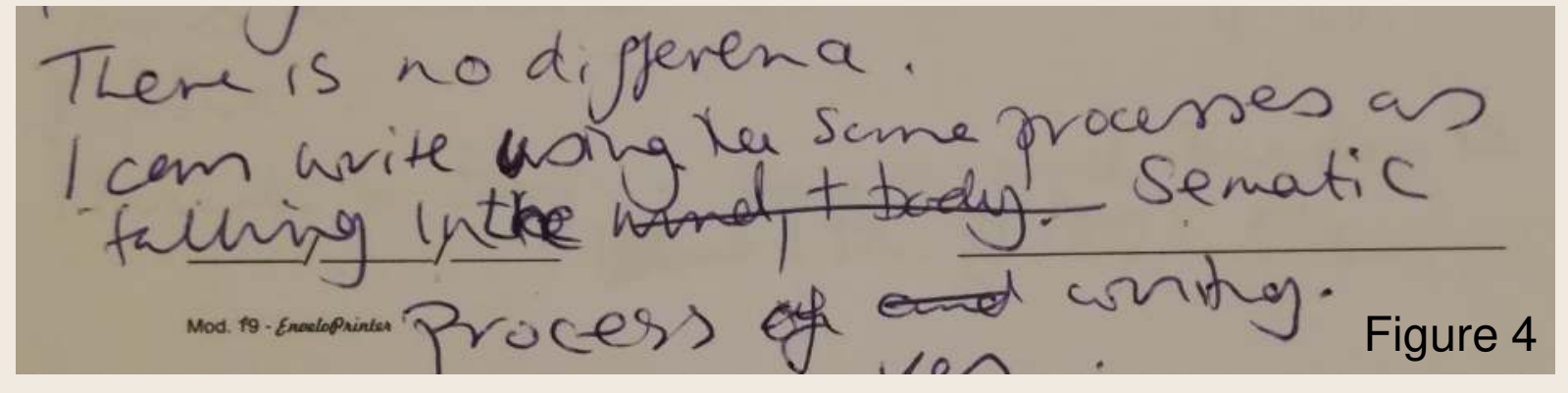

Why don't you want to speak?

No reason other than it is $\mathrm{mt}$ right.

$$
\text { No reason, other han it is my right. }
$$

\section{Conclusions:}

The establishment of a diagnosis for SM in the adult is challenging, particularly at an emergency service, and differential diagnosis of acute mental health conditions, such as psychosis, should be carefully excluded.

\section{Sources:}

1) American Psychiatric Association. (2013). Anxiety Disorders. In Diagnostic and statistical manual of mental disorders (5th ed.). https://doi.org/10.1176/appi.books.9780890425596.dsm05

2) Muris P1,2, Hendriks E3, Bot S3. Children of Few Words: Relations Among Selective Mutism, Behavioral Inhibition, and (Social) Anxiety Symptoms in 3- to 6-Year-Olds. Child Psychiatry Hum Dev. 2016 Feb;47(1):94-101.

3) Holka-Pokorska J, Piróg-Balcerzak A, Jarema M. The controversy around the diagnosis of selective mutism - a critical analysis of three cases in the light of modern research and diagnostic criteria. Psychiatr Pol. 2018 Apr 30;52(2):323-343. 